ISI Impact Factor

(2019-20): 1.628

IC Value (2019): 90.81

$\operatorname{SJIF}(2020)=7.893$

(c) (7) (8)

Copyright@IJCRR

\section{$\bullet$ \\ IJCRR \\ Section: Healthcare \\ Excessive Yawning in a Child During COVID-19 Lockdown Responding to Vitamin D, Nutritional Supplement and Yoga Therapy}

\author{
Patil AD', Patil S², Shinde P $^{3}$
}

'Department of Pharmacology Dr. DY Patil Medical College, Nerul, Mumbai, India; ${ }^{2}$ Consultant Pediatrician, LifeLine Children Hospital, Hudco, Aurangabad, Maharashtra, India; ${ }^{3}$ Consultant Pediatrician, Om Children's Hospital, Vaijapur, Maharashtra

\title{
ABSTRACT
}

Coronavirus Disease (COVID-19) has imposed several restrictions on people of all groups including children. Lockdown has forced the children to stay in the house with limited physical activities, minimal exposure to sunlight and nutritional challenges. This unusual lifestyle may result in the increased incidence of some illnesses in children. We report a case of excessive yawning in a child during the period of lock-down due to COVID-19 which responded to vitamin D supplement, multi-vitamin and mineral supplement and yoga therapy. An 8.5-year-old male child presented with a chief complaint of excessive yawning which started gradually and increased significantly over 15 days. We noted that after nutritional supplementation and yoga therapy, the child showed significant improvement in overall health.

Key Words: COVID-19, Nutritional supplement, Physical activity, Response, Vitamin D, Yawning

\section{INTRODUCTION}

Severe acute respiratory syndrome coronavirus 2 (SARSCoV-2) causing Coronavirus Disease (COVID-19), first detected in China and subsequently spread to the rest of the world have been a part of the everyday discussion in all sectors since last few months. ${ }^{1}$ COVID-19 has caused some restrictions on people from all age groups including children. Countries have resorted to the option of lock-down for curbing the spread of the virus from person to person. This strategy is useful for limiting the spread of infection. ${ }^{2}$ Alongside this benefit, lockdown and restrictions imposed by the fear of disease transmission may be associated with some undesirable outcomes.

Due to the closure of schools due to compulsory lock-down, children have been in the house for last close to five months. During these days, there have been significant restrictions on their physical activities, out-door games and exposure to sunlight. Possibilities of impact on the physical and mental health of children due to staying in the home for a long time during lockdown have been contemplated. ${ }^{3}$ Significant time being spent in the house also has implications on the nutritional status of the children. Yawning is a stereotyped behaviour and it can be a sign or symptom of some neurological conditions. ${ }^{4}$ Yawning reflects dopaminergic activity, but its complete pathophysiological mechanism is yet to be completely understood. ${ }^{5}$

However, according to the best of our knowledge, there are no studies or case reports of excessive yawning in children responding to vitamin $\mathrm{D}$, nutritional supplementation and yoga therapy.

\section{CASE PRESENTATION}

An 8.5-year-old male child presented with a chief complaint of excessive yawning which started gradually and increased significantly over 15 days. Yawning at the time of consultation was severe (almost 4-5 yawns per hour) resulting in fatigue. At times, the child used to cry due to excessive yawning, possibly because of fatigue. There were no other complaints except mild irritability.

Except for the history of febrile convulsion, the child did not have any significant medical history. The child is born by normal delivery without any developmental abnormality. School performance to date is satisfactory. At the time of consultation, parents provided a history that the child hasn't gone out of the house for the last three months because of

\section{Corresponding Author:}

Patil AD, Department of Pharmacology, Dr. DY Patil Medical College, Nerul, Mumbai, India.

Phone: 9920449433; Email: anantd1patil@gmail.com; anant.patil@dypatil.edu

ISSN: 2231-2196 (Print)

Received: 21.10 .2020
ISSN: 0975-5241 (Online)

Revised: 13.12 .2021
Accepted: 05.02 .2021
Published: 30.03 .2021 
COVID-19. He was engaged for the last three months in inhouse activities such as indoor games, reading and watching television. Physical activities were limited to in-house playing. History of boredom was present.

Due to restrictions in travel, telephonic consultation was given to the child. Laboratory investigations were also not conducted considering the parent's reluctance to take the child to a hospital for investigations due to apprehensions of catching SARS-CoV-2. The child was advised to take vitamin D $60,000 \mathrm{IU} /$ per week for six weeks. He was also advised to take multi-vitamin and mineral supplementation. The child was also suggested to start in-house exercises and yoga.

After nutritional supplementation and yoga therapy, the child showed significant improvement in overall health. Reduction in frequency of yawning was started four to five days after starting vitamin $\mathrm{D}$ and nutritional supplement. A significant reduction in yawning and irritability was observed after about two weeks of therapy. After about one month of this treatment, yawning was almost abolished.

\section{DISCUSSION}

We present a case of excessive yawning which responded to nutritional supplementation and yawning. Pathological yawning is triggered by a specific reason. The causes may be neuro-psychiatric, gastrointestinal, or metabolic or iatrogenic. ${ }^{6}$ Yawning can be a feature of a neurological condition such as stroke and epilepsy. Rarely, it can be a symptom of a brain tumour. ${ }^{7}$ In our case, there was no other relevant history suggestive of these disorders, hence these causes were ruled out. The patient was not receiving any medicine, hence drug-induced yawning was excluded. ${ }^{4}$ Migraine was also excluded as there were no other classical symptoms of migraine or family history. ${ }^{5}$ Contagious yawning i.e. yawning triggered involuntarily by observing another person yawn was also ruled out. ${ }^{7}$

Yawning can be associated with fatigue and boredom. ${ }^{6}$ In our case, both were present. Excessive yawning can also be due to metabolic cause. ${ }^{8}$ Vitamin D deficiency is a global phenomenon. Community-based studies in India have shown the prevalence of vitamin D deficiency in $50 \%$ to $94 \%$ of people. ${ }^{9}$ Relevance of vitamin $\mathrm{D}$ for bone health is well established. Evidence showing the relation of vitamin D with mental health is also accumulating..$^{10}$ Biosynthesis of neurotransmitters and neurotrophic factors is modulated by vitamin D. ${ }^{11}$ These neurohormonal effects may have a relation with mental health. ${ }^{12}$ At this moment, the relevance of vitamin D in yawning is not known. We contemplated these causes contributing to yawning.

Considering the high prevalence of vitamin D deficiency in India, history of inadequate sun exposure for almost three months during the lockdown period, unusual irritability in the child, vitamin D supplementation was advised to the child. ${ }^{13}$ Considering the possibility of irritability due to nutritional deficiency and mood-related changes multi-vitamin and the multi-mineral supplement was advised along with yoga therapy. With the suggested treatment, the child showed significant improvement over a period of time. A significant reduction in the frequency of yawning was observed after about two weeks of starting the treatment and completely stopped after about a month.

We feel children with fatigue need a thorough assessment to find any treatable underlying medical condition. It should be noted that fatigue and sleepiness may attributable to lifestyle issues. ${ }^{14}$ In our case, there was a clear history of change in the lifestyle over the last few months. As multiple nutritional supplements (vitamin D, multi-vitamin and minerals), it is difficult to establish the cause and effect of yawning with any specific element in the therapy.

\section{CONCLUSION}

According to the best of our knowledge, this is a unique case of excessive yawning responding to vitamin $\mathrm{D}$, multi-vitamin and mineral supplement and yoga therapy. A careful history can provide important clues for the aetiology of yawning. Clinicians should consider the differential diagnosis of nutritional deficiency in children with excessive yawning.

\section{ACKNOWLEDGEMENT}

Authors thank all the scholars whose articles are cited and included in references to this manuscript. The authors are also grateful to authors/editors / publishers of all those articles and journals from where the literature for this article has been reviewed and discussed.

\section{Conflict of Interest: None}

\section{Source of Funding: None}

Authors' Contribution: All authors contributed to the conceptualization of the manuscript, collection of data, literature search and preparation of the manuscript. All authors reviewed and approved the manuscript.

\section{REFERENCES}

1. Liu YC, Ku RL, Shih SR. COVID-19: The first documented coronavirus pandemic in history. Biomed J 2020;43:328-33

2. Atalan A. Is the lockdown important to prevent the COVID-9 pandemic? Effects on psychology, environment and economyperspective. Med Surg (Lond) 2020;56:38-42.

3. Thakur K, Kumar N, Sharma N. Effect of the pandemic and lockdown on mental health of children. Indian J Pediatr 2020;87:552. 
4. Teive HAG, Munhoz RP, Camargo CHF, Walusinski O. Yawning in Neurology: a review. Arq Neuropsiquiatr 2018;76:473-480.

5. Guven B, Guven H, Comoglu SS. Migraine and Yawning. Headache 2018;58:210-216.

6. Gundogdu AA, Ozdemir AO, Ozkan S. Pathological yawning in patients with acute middle cerebral artery infarction: Prognostic significance and association with the infarct location. Balkan Med J 2019;37:24-28

7. Brown BJ, Kim S, Saunders H, Bachamann C, Thompson J, Ropar D, et al. A neural basis for contagious yawning. Curr Biol 2017;27:2713-2717.

8. Krestel H, Bassetti CL, Walusinski O. Yawning-Its anatomy, chemistry, role, and pathological considerations. Prog Neurobiol 2018;161:61-78.

9. Aparna P, Muthathal S, Nongkynrih B, Gupta SK. Vitamin D deficiency in India. J Family Med Prim Care 2018;7:324-330.
10. Focker M, Antel J, Ring S, Hahn D, Kanal O, Ozturk D, et al. Vitamin D and mental health in children and adolescents. Eur Child Adolesc Psychiatry 2017;26:1043-1066.

11. Anjum I, Jaffery S S, Fayyaz M, Samoo Z, Anjum S. The role of vitamin D in brain health: A mini literature review. Cureus 2018;10(7):e2960.

12. Weydert JA. Vitamin D in children's health. Children 2014;1:208-226.

13. S Balasubramanian, K Dhanalakshmi, Amperayani S. Vitamin $\mathrm{D}$ deficiency in childhood - a review of current guidelines on diagnosis and management. Indian Pediatr 2013;50:669-675.

14. Findlay SM. The tired teen: A review of the assessment and management of the adolescent with sleepiness and fatigue. Paediatr Child Health 2008;13:37-42. 